\title{
An Emphasis on Neurosciences
}

\author{
Ronald G. Amedee, MD, FACS
}

Designated Institutional Official, Office of Graduate Medical Education, Division of Ochsner Academics, Ochsner Clinic Foundation, New Orleans, LA; Head of Clinical School and Professor, The University of Queensland Faculty of Medicine, Ochsner Clinical School, New Orleans, LA; Editor-in-Chief, Ochsner Journal

Springtime is the land awakening. The March winds are the morning yawn. -Lewis Grizzard

In our first issue of the Ochsner Journal in 2019, we once again highlight work being done in an Ochsner Center of Excellence, namely Neurosciences. The Ochsner Neuroscience Institute has a reputation for leading-edge, patient-centered care that has made the center a nationwide destination for patients of all ages who have the most complex and rare neurologic conditions. In fact, the Ochsner Neuroscience Institute is the only center of its kind in the Gulf South to achieve a national ranking from U.S. News \& World Report in neurology and neurosurgery. Expert clinicians armed with the latest technology treat hundreds of patients each year. The multispecialty team of nationally recognized experts includes clinicians from neurology, neurosurgery, neurocritical care, neuroradiology, and physical medicine and rehabilitation. The Institute's slogan speaks for itself: "Neurological diseases can be relentless. So are we."

Our collection of neurosciences articles features two original research reports. Nguyen and Sulaiman contributed "Transforming Growth Factor Beta 1 Regulates Fibroblast Growth Factor 7 Expression in Schwann Cells," and Noor et al elucidate "Comorbidities Related to Clinical Outcomes in Patients With Acute Ischemic Stroke Undergoing Mechanical Thrombectomy: Review of Literature and Experience at a Single Comprehensive Stroke Center."

The three literature reviews in this issue examine the biomarkers of pineal region tumors, gadolinium deposition, and the sphenopalatine ganglion block and radiofrequency ablation.

Three important case series and one case report address deficits in the literature. Scullen et al present two cases in which a novel technique of coregistered imaging navigation was used in the resection of spinal cord tumors. Denis et al present three cases and a detailed surgical technique for using laminoplasty to implant cervical spinal cord stimulators in patients with cervical spondylosis and fusion. Coote et al show how 3-dimensional printed models were used in preoperative planning for three complex pediatric spinal deformity surgeries. Valle-Giler et al have developed a novel variation to an established approach for resection of an arteriovenous malformation in the atrium that may decrease the risk of neurologic deficits.

This issue also includes a variety of case reports, as well as letters to the editor and a thought-provoking editorial. In addition, we are extremely pleased to once again publish online the abstracts of the Ochsner and Louisiana State University Annual Evidence-Based Practice/Research Conference. The theme of the 2018 nursing conference was "Evidence for Practice: Origins and New Directions," and the abstracts accepted for that event are available at www.ochsnerjournal.org.

Because this is the first issue of the Journal to be published in 2019, this introduction was composed in midJanuary while we in New Orleans (and much of the country) were experiencing the coldest part of the winter season. As we dressed in multiple layers of clothing designed to ensure warmth and our energy bills were soaring, it was hard for many of us to remember that springtime was right around the corner. But a quick look at the calendar revealed that March and the hope of warmer and brighter days were just 6-8 weeks away (we hope). The land will once again awaken and every tree will turn leafy, grass will become green, and flowers will once again brightly bloom. Enjoy! 